$$
\text { Vol. } 1 \text { No.1 (2021) 27-36 }
$$

\title{
Pena Jangkar
}

http://jurnal.amnus-bim.ac.id/index.php/pena-jangkar

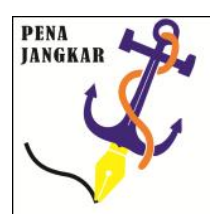

\section{PENERAPAN STANDAR OPERASIONAL PROSEDUR PT. ARPENI PRATAMA OCEAN LINE BANJARMASIN DALAM MELAYANI KEAGENAN KAPAL}

\author{
Wildani Khotami ${ }^{1}$, Rusdi Bahar ${ }^{2}$, Musdalifah Ajeng Pratiwi ${ }^{3}$
}

Akademi Maritim Nusantara Banjarmasin, Indonesia

\begin{tabular}{l}
\hline Info Artikel \\
\hline Sejarah Artikel: \\
Diterima \\
12/08/2021 \\
Disetujui \\
16/08/2021 \\
Dipublikasikan \\
05/09/2021 \\
\hline Keywords: \\
Oprasional prosedur, \\
Pelayanan, Keagenan \\
Kapal
\end{tabular}

Abstrak

Penelitian ini bertujuan untuk (1) Untuk mengetahui penerapan standar operasional prosedur PT. Arpeni Pratama Ocean Line Banjarmasin (2) Untuk mengetahui dalam melayani keagenan kapal jenis serta yang memiliki tanggung jawab untuk melayani dan menyediakan jasa untuk kegiatan kedatangan dan keberangkatan kapal berupaya mewujudkan kinerja pelayanan publik di lingkungan unit kerja PT. Arpeni Pratama Ocean Line Banjarmasin yang terukur dan dapat dievaluasi keberhasilannya. PT. Arpeni Pratama Ocean Line Banjarmasin perlu memiliki dan menerapkan SOP (Standar Operasional Prosedur) dalam melayani kapal-kapal yang masuk area Taboneo sampai Kelanis. SOP (Standar Operasional Prosedur) adalah pedoman atau acuan untuk melaksanakan tugas pekerjaan sesuai dengan fungsi dan tugasnya berdasarkan indikator indikator teknis, administrasif dan prosedural sesuai dengan tata kerja, prosedur kerja dan sistem kerja pada unit kerja yang bersangkutan.Adapun visi dari PT. Arpeni Pratama Ocean Line Banjarmasin adalah Menjadi pelopor transportasi dan logistik terpadu serta mengembangkan manusia handal Indonesia untuk memenuhi kebutuhan anda dan misi PT. Arpeni Pratama Ocean Line Banjarmasin adalah Penyedia solusi transportasi dan logistik terpadu melalui keunggulan operasional yang kompetitif.

\begin{abstract}
This study aims to (1) To determine the application of standard operating procedures PT. Arpeni Pratama Ocean Line Banjarmasin (2) To find out in serving the ship type agency and those who have the responsibility to serve and provide services for ship arrivals and departures, seek to realize the performance of public services in the work unit environment of PT. Arpeni Pratama Ocean Line Banjarmasin which is measurable and can be evaluated for its success. PT. Arpeni Pratama Ocean Line Banjarmasin needs to have and implement a SOP (Standard Operating Procedure) in serving ships entering the Taboneo to Kelanis area. SOP (Standard Operating Procedure) is a guideline or reference for carrying out work tasks in accordance with their functions and duties based on technical, administrative and procedural indicators in accordance with work procedures, work procedures and work systems in the work unit concerned. The vision of PT. Arpeni Pratama Ocean Line Banjarmasin is to be a pioneer of integrated transportation and logistics and to develop reliable Indonesian people to meet your needs and the mission of PT. Arpeni Pratama Ocean Line Banjarmasin is a provider of integrated transportation and logistics solutions through competitive operational advantages.
\end{abstract}

(C) 2021 Akademi Maritim Nusantara Banjarmasin

\footnotetext{
Alamat korespondensi:

E-mail: wildanikhotami99@gmail.com
} 


\section{PENDAHULUAN}

Kebutuhan akan jasa angkutan laut semakin lama semakin meningkat, baik jumlahnya maupun macamnya. Usaha-usaha dalam pembangunan sarana angkutan laut yang dilakukan sampai saat ini adalah merupakan cerminan dalam mengatasi peningkatan kebutuhan tersebut. Bagian komponen dari sistem angkutan laut adalah pelabuhan, dimana pelabuhan laut merupakan salah satu subsistem transportasi laut yang mempunyai fungsi utama, yaitu sebagai tempat yang aman untuk berlabuh dan bertambatnya kapalkapal serta sebagai terminal transfer barang dan penumpang melalui angkutan darat dan angkutan laut.

Pelabuhan merupakan suatu simpul sistem transportasi laut dan darat, karena sifatnya sebagai tempat peralihan moda angkutan, maka pelabuhan harus disambung dengan sistem darat dan dilengkapi dengan berbagai macam kemudahan, antara lain tempat yang aman untuk berlabuhnya kapal, pelayanan kapal selama berlabuh dan ketika akan melanjutkan pelayaran, jasa terminal untuk muatan dalam proses peralihan dari kapal ke angkutan darat (truk). Berdasarkan hal tersebut maka diperlukanlah sarana dan prasarana yang dapat menunjang kelancaran alat pelayanan ekspor dan impor.

Dengan menimbang biaya transportasi dalam mengirim barang muatan berat, maka para eksportir dan importir di berbagai Negara cenderung memilih moda transportasi laut seperti kapal untuk mengangkut barang yang mereka perdagangkan dan tentunya akan dibawa dalam jumlah banyakdan murah dibandingkan transportasi melalui darat dan udara yang dinilai lebih mahal.

Semakin pesatnya pelayanan jasa di Indonesia, maka diperlukanlah perusahaan jasa keagenan untuk kapal yang memiliki standar pelayanan yang baik dan selama ini/memang jarang ditemukan di pelabuhan di Indonesia. Keagenan adalah pihak yang mewakili untuk dan atas nama perusahaan pelayaran atau kapal dalam mempersiapkan segala sesuatu agar kegiatan kapal selama di pelabuhan dapat berjalan sesuai dengan rencana, mempersiapkan fasilitas sebelum kapal tiba dan menyelesaikan kewajiban - kewajiban finansial setelah kapal berangkat, sehingga dapat memberikan pelayanan sepenuhnya terhadap kepentingan kapal selama di pelabuhan.Kota Banjarmasin adalah sebuah kota terbesar di Provinsi Kalimantan Selatan, Indonesia.

PT. Arpeni Pratama Ocean Line Banjarmasin sebagai Perusahaan Pelayaran dan peyedia jasa keagenan kapal serta yang memiliki tanggung jawab untuk melayani dan menyediakan jasa untuk kegiatan kedatangan dan keberangkatan kapal berupaya mewujudkan kinerja pelayanan public di lingkungan unit kerja PT. Arpeni Pratama Ocean Line Banjarmasin yang terukur dan dapat dievaluasi keberhasilannya, PT. Arpeni Pratama Ocean Line Banjarmasin perlu memiliki dan menerapkan SOP (Standar Operasional Prosedur) dalam melayani kapal-kapal yang masuk area Taboneo sampai Kelanis.

SOP (Standar Operasional Prosedur) adalah pedoman atau acuan untuk melaksanakan tugas pekerjaan sesuai dengan fungsi dan tugasnyaberdasarkan indikator indikator teknis, administrasif dan prosedural sesuai dengan tata kerja, prosedur kerja dan sistem kerja pada unit kerja yang bersangkutan. Tujuan dibuatnya SOP (Standar Operasional Prosedur) oleh PT. Arpeni Pratama Ocean Line Banjarmasin menciptakan komitment mengenai apa yang dikerjakan oleh satuan unit kerja instansi PT. Arpeni 
Pratama Ocean Line Banjarmasin untuk mewujudkan good services, dimana kapal-kapal yang akan melakukan kegiatan keluar atau masuk area perairan Taboneo dan Kelanis harus sesuai dengan SOP (Standar Operasional Prosedur) yang berlaku di PT. Arpeni Pratama Ocean Line Banjarmasin dan juga memenuhi syarat oleh syahbandar setempat.

\section{METODE PENELITIAN}

Penelitian ini termasuk jenis penelitian kualitatif yang bersifat deskriptif menurut Sugiyono, penelitian kualitatif adalah penelitian dimana peneliti ditempatkan sebagai instrument kunci, teknik pengumpulan data dilakukan secara penggabungan data bersifat edukatif.

Penelitian ini bertujuan untuk mendeskripsikan PT. Arpeni Pratama Ocean Line Banjarmasin sebagai Perusahaan Pelayaran dan peyedia jasa keagenan kapal serta yang memiliki tanggung jawab untuk melayani dan menyediakan jasa untuk kegiatan kedatangan dan keberangkatan kapal berupaya mewujudkan kinerja pelayanan public.

Sumber data dari penelitian metode yang telah dilakukan dari berbagai sumber dengan beragam cara berupa obsevasi, wawancara, maupun studi dokumen yang berkaitan dengan keadaan dilapangan sehingga Sumber data penelitian ini adalah PT. Arpeni Pratama Ocean Line Banjarmasin. Data yang diperoleh dianalisis menggunakan analisis deskritif.

\section{HASIL DAN PEMBAHASAN}

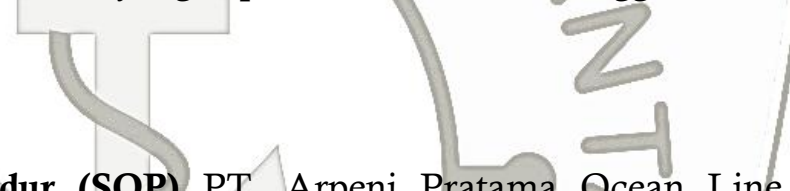

Standar Operasional Prosedur (SOP) PT. Arpeni Pratama Ocean Line Dalam Melayani Keagenan Kapal dalam Peraturan Menteri Perhubungan Republik Indonesia No. 65 tahun 2019 tentang Penyelenggaraan dan Pengusahaan Keagenan Kapal Pasal 1 Ayat 4 yang berbunyi: "Agen umum adalah perusahaan angkutan laut nasional atau perusahaan nasional yang khusus didirikan untuk melakukan usaha keagenan kapal, yang ditunjuk oleh perusahaan angkutan laut asing untuk mengurus kepantingan kapalnya selama berada di Indonesia".Agen mempunyai tugas mengurus semua kebutuhan kapal selama di pelabuhan, hal tersebut dimaksudkan agar kapal selama berada di pelabuhan berjalan lancar dan tidak mengalamihambatan. Tugas pokok agen pelayaran seperti, Mengusahakan muatan, Mengurus bongkar muat barang, Mengurus kebutuhan awak kapal (misalnya ABK sakit memerlukan ambulan untuk pengobatan, pengurusan dahsuskim untuk crewdan tenaga ahli asing merupakan salah satu tugas dari agen), Mengurus Clearance kapal masuk dan keluar di pelabuhan, Mengurus kebutuhan kapal, bunker, air tawar, bahan bakar dan bahan makanan dan Menyelesaikan dokumen-dokumen muatan.

Prinsip itu, berlaku juga di Indonesia, maka berdasarkan penunjukan tersebut, agen melaksanakan tugas sesuai dengan perjanjian yang telah disepakati. Tugas agen dalam pelayanan operasional kapal-kapal milik prinsipal seperti pada Port information (port facility, port formality, custom of port), Keperluan kapal, seperti bunker, air, provision, repair, maintenance, crewing, surat-surat, sertifikat kapal dan lain-lain. Penyelesaian dokumen, Bill of Lading (B/L), manifest, hatch list, stowage plan, crew list, dokumen bongkar muat, ship husbanding (in \& out clearance, Imigrasi, Bea Cukai, kesehatan pelabuhan, port administratordan dokumen kapal lainnya), Permintaan advance 
paymentuntuk expenses, cargo expenses, keperluan kapal dan lain-lain, serta Memberikan informasi kepada principalterkait kedatangan dan keberangkatan kapal.

1. Standar Operasional Prosedur Dalam Peraturan Menteri Perhubungan Nomor : KM. 21 Tahun 2007 tentang Sistem dan Prosedur Pelayanan Kapal, Barang dan Penumpang pada Pelabuhan Laut yang diselenggarakan oleh Unit Pelaksana Teknis (UPT) Kantor Pelabuhan Pasal 1 Ayat 1 yang berbunyi : "Sistem dan Prosedur Pelayanan Kapal, Barang dan Penumpang adalah tata cara pelayanan operasional yang mengatur keluar masuk kapal, kegiatan bongkar muat, keluar/masuk barang dan orang dipelabuhan, yang dilakukan untuk menjamin terselenggaranya ketertiban dan kelancaran kegiatan operasional pelabuhan.

Setiap kegiatan yang dilakukan, untuk mempermudah pengguna jasa dalam pengurusan, maka digunakan prosedur. Prosedur merupakan tata cara kerja untuk menjalankan suatu pekerjaan. Berikut Standar Operasional Prosedur (SOP) yang terdapat 3 pedoman yang dipergunakan pada kegiatan operasional perusahaan PT Arpeni Pratama Ocean Line Banjarmasin, antara lain: Menunjang kelancaran dalam proses pelaksanaan tugas dan kemudahan pengendalian, Mempertegas tanggung jawab pelaksanaan tugas serta meningkatkan dayaguna dan hasilguna secara berkelanjutan, dan Memberikan informasi pelaksanaan tugas yang dilakukan secara proporsional.

Tahap akhir standar operasional prosedur, dinyatakan sebagai pertanggung jawaban tugas yang dilaksanakan oleh bagian operasional meliputi:

a. Prosedur Kerja disusun untuk menghasilkan kegiatan yang maksimal.

- Rangkaian Kerja, kegiatan operasional, pekerja mempunyai rangkaian kerja yang telah dipersiapkan sebagaimana mestinya sebelum pelaksanaan kegiatan.

- Keterkaitan, dalam melaksanakan sebuah prosedur diperlukan keterkaitan antara satu tugas dan tanggung jawab mempunyai yang hubungan erat di dalam pelaksanaan kerja.

- Berurutan Bertahap, urutan tahapan secara jelas, sehingga mempermudah bagi pelaksana kegiatan.

- Metode atau Cara, merupakan cara - cara yang harus ditempuh oleh bagian operasional untuk melaksanakan kegiatan operasional.

- Penyelesaian, bagian operasional diwajibkan untuk melakukan penyelesaian tugas yang diberikan dan memberikan laporan administrasi umum maupun keuangan.

b. Prinsip - prinsip Prosedur Kerja untuk memperkuat tata cara kerja, perusahaan mempunyai beberapa prinsip yang wajib diikuti oleh semua bagian. Berikut merupakan prinsip yang dilakukan oleh pekerja pada perusahaan PT. Arpeni Pratama Ocean Line Banjarmasin adalah:

- Prinsip Akuntabilitas (Accountability) Prinsip akuntabilitas adalah prinsip yang mengutamakan perhitungan-perhitungan yang matang, memuat kewenangankewenangan yang dimiliki semua pihak yang terlibat dalam organisasi dengan memahami visi dan misi, target perusahaan, peran, tugas, tanggung jawab, menaati sistem dan prosedur, melakukan proses cek and balance, melakukan penilaian kinerja, pertanggungjawaban dan mendokumentasikan hasil pekerjaan. 
- Prinsip Pertanggung Jawaban (Responsibility) Prinsip pertanggung jawaban adalah prinsip yang merujuk pada pertanggung jawaban atau keadaan untuk diminta pertanggung jawaban atas suatu pekerjaan.

2. Pengurusan Pengurusan sebagai suatu proses yang mana sebuah kumpulan yang bekerjasama untuk mengarahkan tindakan orang lain kearah mencapai matlamat bersama. Konsep Pengurusan banyak digunakan dalam sebuah perusahaan pelayaran merujuk kepada satu proses untuk mencapai tujuan organisasi melalui kerjasama antara semua individu yang berkaitan serta sumber organisasi lain. Konsep pengurusan merujuk kepada aspek-aspek berikut :

- Satu proses dan aktivitas sosial yang berterusan dan saling bergantung antara semua komponen dalam sebuah organisasi dan juga di luar organisasi.

- Tujuan utama proses dan aktivitas tersebut adalah untuk mencapai matlamat organisasi yang formal.

- Proes pencapaian tujuan tersebut adalah melalui manusia dan sumber organisasi lain.

Proses dan aktivitas utama yang terlibat ialah perancangan, penyusunan, penyelarasan, pengarahan, dan pengawalan.

Dalam proses pengurusan dokumen (clearance in-out) perusahaan keagenan kapal berkaitan dengan beberapa instansi pemerintahan untuk melakukan pengurusan dokumen, adapun instansi - instansi tersebut :

KSOP (Kantor Kesyahbandaran Otoritas Pelabuhan)

Peraturan Menteri Perhubungan Republik Indonesia Nomor : PM. 51 Tahun 2015 tentang Penyelenggaran Pelabuhan Laut Pasal 1 Ayat 12 yang berbunyi : "Kesyahbandaran dan Otoritas Pelabuhan adalah lembaga Pemerintah di pelabuhan yang mempunyai tugas melaksanakan pengawasan dan penegakan hukum di bidang keselamatan dan keamanan pelayaran, koordinasi kegiatan pemerintahan di pelabuhan, serta pengaturan, pengendalian, dan pengawasan kegiatan kepelabuhanan pada pelabuhan yang diusahakan secara komersial." Selanjutnya KSOP diatur lagi di dalam ayat 19 yang berbunyi: "Syahbandar adalah pejabat Pemerintah dipelabuhan yang diangkat oleh Menteri dan memiliki kewenangan tertinggi untuk menjalankan dan melakukan pengawasan terhadap dipenuhinya ketentuan peraturan perundang-undangan untuk menjamin keselamatan dan keamanan pelayaran.'

Adapun organisasi dan tugas KSOP dituangkan dalam Peraturan Menteri Perhubungan Republik Indonesia Nomor : PM. 51 Tahun 2015 tentang Penyelenggaran Pelabuhan Laut Pasal 30 yang berbunyi :

- Petugas Tata Usaha mempunyai tugas melakukan urusan keuangan, kepegawaian dan umum, hukum dan hubungan masyarakat serta pelaporan Kantor Kesyahbandaran dan Otoritas Pelabuhan.

- Petugas Status Hukum dan Sertifikasi Kapal mempunyai tugas melakukan penyiapan bahan pengukuran, pendaftaran, balik nama, hipotek dan surat tanda kebangsaan, penggantian bendera kapal serta pemasangan tanda selar dan melakukan pemeriksaan, penilikan rancang bangun kapal, pengawasan pembangunan, perombakan dan dockingkapal, pemeriksaan dan pengujian nautis, teknis, radio, elektronika kapal, 
penghitungan dan pengujian stabilitas kapal, percobaan berlayar, pengujian peralatan, verifikasi dan penyiapan bahan penerbitan sertifikat keselamatan kapal, sertifikat manajemen keselamatan dan pencegahan pencemaran dari kapal, pembersihan tangki serta perlindungan ganti rugi pencemaran.

- Petugas Keselamatan Berlayar, Penjagaan dan Patroli mempunyai tugas melakukan penilikan pemenuhan persyaratan pengawakan kapal, penyiapan bahan penerbitan dokumen kepelautan, perjanjian kerja laut dan penyijilan awak kapal serta perlindungan awak kapal, pelaksanaan pengawasan tertib bandar, pergerakan kapal (shifting), pemanduan dan penundaan kapal di perairan pelabuhan dan tertib berlayar, lalu lintas keluar masuk kapal, kapal asing (port State control), flagState controldan pemenuhan persyaratan kelaiklautan kapal dan penerbitan Surat Persetujuan Berlayar, penjagaan, pengamanan dan penertiban embarkasi dan debarkasi penumpang di pelabuhan, pengawasan kegiatan bongkar muat barang khusus, barang berbahaya, pengisian bahan bakar serta limbah bahan berbahaya dan beracun (B3), pembangunan fasilitas pelabuhan serta pengerukan dan reklamasi, patroli di perairan pelabuhan, pengawasan dan pengamanan terhadap keselamatan kapal yang masuk keluar pelabuhan, kapal sandar dan berlabuh, penyiapan bahan koordinasi dan pemberian bantuan pencarian dan penyelamatan (Search And Rescue/ SAR), penanggulangan pencemaran laut serta pencegahan dan pemadaman kebakaran di perairan pelabuhan, pengawasan kegiatan alih muat di perairan pelabuhan, saluage dan pekerjaan bawah air,pelaksanaan pemeriksaan dan verifikasipelaksanaan pemeriksaan dan verifikasi sistem keamanan kapal dan fasilitas pelabuhan(International Ship and Port Facility SecnrityCode / ISPSCode), penyiapan bahan pemeriksaan pendahuluan pada kecelakaan kapal, serta pelaksanaan penyidikan tindak pidana di bidang pelayaran sesuai dengan ketentuan peraturan perundang-undangan.

- Petugas Lalu Lintas dan Angkutan Laut, dan Usaha Kepelabuhanan mempunyai tugas melakukanpenyiapan bahan pengaturan, pengendalian dan pengawasan kegiatan lalu lintas dan angkutan laut, tenaga kerja bongkar muat, pengawasan kegiatan keagenan dan perwakilan perusahaan angkutan kapal asing, penjaminan kelancaran arus barang, keamanan dan ketertiban di pelabuhan, pengaturan dan penyelenggaraan lalu lintas kapal keluar/ masuk pelabuhan melalui pemanduan kapal, penyiapan bahan pengawasan dan evaluasi penerapan standar penggunaan peralatan kegiatan bongkar muat serta Tenaga Kerja Bongkar Muat (TKBM), penyusunan Rencana Induk Pelabuhan, rencana dan program pembangunan dan pemeliharaan sarana prasarana pelabuhan, penjaminan dan pemeliharaan kelestarian lingkungan di pelabuhan, program pembangunan dan pemeliharaan sarana dan prasarana pelayanan jasa kepelabuhanan yang belum disediakan oleh Badan Usaha Pelabuhan serta penyusunan desain konstruksi fasilitas pokok pelabuhan dan fasilitas penunjang kepelabuhanan, pelaksanaanpengaturan, pengendalian dan pengawasan penggunaan lahan daratan dan perairan pelabuhan serta Daerah Lingkungan Kerja dan Daerah Lingkungan Kepentingan pelabuhan, fasilitas dan operasional pelabuhan, penetapan dan evaluasi standar kinerja operasional pelayanan jasa, penyiapan bahan pemberian rekomendasi persetujuan lokasi pelabuhan, pengelolaan terminal untuk kepentingan sendiri serta 
peningkatan kemampuan terminal dan operasional pelabuhan 24 (dua puluh empat) jam, penyusunan pemberian konsesi, atau bentuk lainnya kepada Badan Usaha Pelabuhan serta penyediaan dan/atau pelayanan jasa kepelabuhanan yang belum disediakan oleh Badan Usaha Pelabuhan, penyusunan dan pengusulan tarif penggunaan daratan dan/atau perairan, fasilitas pelabuhan serta jasa kepelabuhanan, analisa dan evaluasi pembangunan penahan gelombang, alur pelayaran, jaringan jalan, dan sarana bantu navigasi pelayaran serta sarana dan prasarana pelayanan jasa kepelabuhanan yang diperlukan oleh pengguna jasa yang belum disediakan oleh Badan Usaha Pelabuhan dan penyusunan sistem dan prosedur pelayanan jasa kepelabuhanan, usaha jasa terkait dengan kepelabuhanan dan angkutan di perairan serta penyediaan dan pengelolaan sistem informasi angkutan di perairan dan sistem informasi pelabuhan.

Navigasi

Dalam Peraturan Pemerintah Republik Indonesia Nomor 5 Tahun 2010 Tentang Kenavigasian Pasal 1 Ayat 1 yang berbunyi : "Kenavigasian adalah segala sesuatu yang berkaitan dengan Sarana Bantu Navigasi-Pelayaran, Telekomunikasi-Pelayaran, hidrografi dan meteorologi, alur dan perlintasan, pengerukan dan reklamasi, pemanduan, penanganan kerangka kapal, salvage, dan pekerjaan bawah air untuk kepentingan keselamatan pelayaran kapal".

Tugas dan Tanggung Jawab Navigasi terdapat dalam Pasal 4 Ayat 2 yag berbunyi baik itu, alur-pelayaran; Sarana Bantu Navigasi-Pelayaran; telekomunikasi-pelayaran; pemanduan; dan pemberian pelayanan meteorology

Berikut penerpan Standar Operasional Prosedur PT. Arpeni Pratama Ocean Line saat melayani keagenan kapal:

Kedatangan Kapal

Managemen pelayanan yang baik akan menghasilkan output yang memiliki nilai mendekati sempurna. Hal ini juga berlaku dalam proses pelayanan kapal khususnya proses port clearance pada pelayanan kapal masuk, pindah maupun keluar. Sistem dan prosedur yang dibuat berdasarkan keadaan di lapangan terkait waktu kedatangan, lamanya bongkar muat juga meliputi waktu keberangkatan kapal yang semua itu memiliki kajian dalam memutuskannya dan juga terkait masalah safety pada kru kapal yang menjadi bagian dari IMO (International-Maritim Organization). Service Level Agreement (SLA) merupakan kesepakatan bersama melaksanakan target waktu respon atas permintaan layanan kapal dan barang dari seluruh instansi terkait di pelabuhan menuju kualitas layanan yang lebih baik.

Batasan waktu yang diberikan berdasarkan Surat Keputusan Direktorat Jenderal Perhubungan Laut tentang pada pelayanan kapal di pelabuhan Pelayanan Kapal Masuk Ketika kapal dari suatu daerah memasuki daerah lain (pelabuhan), kapal tersebut harus mematuhi setiap ketentuan pelabuhan yang menjadi tujuannya. Hal ini merupakan bagian dari proses port clearance sebagai kedaulatan suatu Negara.

Pihak pelayaran harus mampu melayani kapal-kapal yang diageninya sesuai dengan prosedur pelayanannya sehingga ketika kapal tiba dan hendak berlabuh, tidak menemukan kesulitan yang akan berakibat lamanya mekanisme proses bongkar muat pelabuhan. 
Kapal Pindah Ketika kapal masuk dalam suatu pelabuhan dan sudah melakukan proses penyandaran, tidak tertutup kemungkinan terjadi perubahan tempat tampab yang menyebabkan kapal harus berpindah. Dalam hal ini umumnya lebih disebabkan karena kurang siapnya infrastruktur pelabuhan sehingga ketika kapal sudah sandar terpaksa harus pindah. Kronologis perpindahan kapal baik Penyampaian Permintaan Kapal Pindah pada dokumen PSAD/PPKB dari Perusahaan Pelayaran (Agen). Paling lambat disampaikan 4 jam sebelum kapal bergerak dari tempat tambat pertama atau sebelumnya ke tempat tambat kedua atau berikutnya. Pada in house Pelindo mengecek sarana pemanduan dan penambatan serta penyediaan informasi posisi penggunaan tambatan secara grafis via portal Portnet, pada Penetapan pelayanan pandu, tunda dan tambat untuk kapal pindah oleh Pelindo. Paling lambat 1 jam sejak PPKB/PSAD diterima. Pada in house sistem Pelindo dilakukan pengecekan saldo CMS, posisi piutang dan pelunasan upper Perusahaan Pelayaran (agen) yang bersangkutan. Pada Penerbitan Surat Pengawasan Olah Gerak (SPOG) dari Adpel. Paling lambat 1 jam sejak respon penetapan pelayanan pandu, tunda dan tambat diterbitkan oleh Pelindo. Sebelum penerbitan SPOG dimungkinkan ada pengecekan fisik kapal oleh Adpel terkait dengan keseimbangan kapal, posisi muatan diatas kapal, dan lain-lain. Serta Penerbitan Surat Perintah Kerja pemanduan dan penambatan. Paling lambat 30 menit sejak SPOG diterbitkan Adpel. Service Level Agreement (SLA) pelayanan pemanduan dan penambatan secara terinci diatur dalam sistem dan prosedur internal Pelindo.

Keberangkatan kapal Setelah proses bongkar muat pelabuhan maka pihak Perusahaan Pelayaran harus mempersiapkan segala macam dokumen yang digunakan dalam proses keberangkatan kapal dan kepanduan agar kapal dapat keluar dari pelabuhan. Kronologis keberangkatan kapal seperti pada Penyampaian Permintaan Pelayanan Kapal keluar pada dokumen PSAD dari perusahaan Pelayaran via Portal Portnet. Paling lambat 6 jam sebelum kapal bergerak dari tempat tambat ke laut. Pada Penerbitan Surat Izin Kesehatan Berlayar (SIKB) dan izin exit permit bagi crew kapal dari kantor imigrasi. Paling lambat 1 jam sejak PSAD diterima. Surat Izin Kesehatan Berlayar (SIKB) dan izin exit permit dapat diinformasikan lebih awal/ke Pelabuhan tujuan via Portal Portnet. Pada Penyampaian dokumen manifest (outward manifest) dari Perusahaan Pelayaran (Agen). Paling lambat 1 jam sejak bongkar muat selesai dilaksanakan. Dokumen yang dikeluarkan diperiksa kembali sebagai/realisasi muat dari Pelindo.Penerbitan dokumen oleh Ditjen Bea Cukai. Paling lambat 1 jam sejak dokumen manifest diterima. Dokumen manifest dapat diinformasikan lebih awal ke pelabuhan tujuan 5.Penerbitan Surat Izin Berlayar (SIB) dari Adpel. Paling lambat 1 jam. Surat Izin Berlayar (SIB) dapat diinformasikan ke Adpel pelabuhan tujuan. Penetapan Pelayanan Pandu dan Tunda oleh Pelindo. Paling lambat 30 menit sejak SIB diterbitkan. Serta Penerbitan surat SPK Pandu dan tunda oleh pelindo. Service Level Agreement (SLA) pelayanan pemanduan dan penundaan diatur oleh sistem dan prosedur internal Pelindo, termasuk Service Level Agreement (SLA) proses pengolahan data realisasi pelayanan sampai dengan penerbitan nota tagihan jasa kapal dan pelunasannya. 


\section{Kendala yang Terdapat dalam Penerapan Standar Operasional Prosedur (SOP) saat Melayani Keagenan Kapal}

Pada saat penulis melakukan PKL - PRODA ada beberapa kendala yang dihadapi pada saat melayani keagenan kapal, antara lain :

a. Lamanya waktu yang digunakan dalam pengurusan dokumen kapal.

Pengurusan dokumen merupakan salah satu faktor yang sangat berpengaruh terhadap peningkatan pelayanan pada PT. Arpeni Pratama Ocean Line Banjarmasin biasanya terjadi pada saat system down. Jika pengurusan dokumen dapat terselesaikan dengan tepat waktu maka pengguna jasa akan semakin lebih mempercayai perusahaan ini dalam melayani keagenan kapal. Sehingga dapat meningkatkan pendapatan perusahaan. Maka dari itu perlunya peningkatan kualitas dan juga menambah jumlah Sumber Daya Manusia agar proses pengurusan dokumen kapal dapat terlaksana dengan lancar dan tepat waktu.

b. Kurangnya keterampilan yang dimiliki oleh karyawan.

Selain jumlah sumber daya manusia, faktor keterampilan juga menjadi salah satu nilai tambah bagi perusahaan. Perusahaan PT. Arpeni Pratama Ocean Line Banjarmasin merupakan perusahaan keagenan yang menangani kapal vessel dan tugboat, secara tidak langsung hal itu membuat karyawan perusahaan harus memiliki keterampilan dalam hal perhitungan proses bongkar muat pada kapal tugboat. Selain itu karyawan juga harus memilki keterampilan mengenai keagenan kapal agar membuat pelayanan kapal pada perusahaan dapat meningkat. Namun menurut penelitian penulis, karyawan pada perusahaan masih belum proesional dalam mengageni keagenan kapal.

c. Dalam Undang - Undang 5 Tahun 2014 Pasall1 tentang Aparatur Sipil Negara yang berbunyi:

Pegawai Aparatur Sipil Negara bertugas :

melaksanakan kebijakan publik yang dibuat oleh Pejabat Pembina Kepegawaian sesuai dengan ketentuan peraturan perundang-undangan;

memberikan pelayanan publik yang profesional dan berkualitas; dan

mempererat persatuan dan kesatuan Negara Kesatuan Republik Indonesia.

Kendala yang terdapat disini adalah dalam melayani kedatangan dan keberangkatan kapal pihak keagenan harus mengurus ke kantor syahbandar untuk memperoses permohonan pengajuan walaupun itu sistem manual ataupun inaportnet. Dalam kepengurusan dokumen tentunya sangat berpengaruh pada pelayanan yang diberikan KSOP kepada agen, ada saja biasanya pada saat pengurusan permohonan pihak pelayanan dibidang pelayanan publik tersebut tidak berada di tempat, itu yang membuat pengurusan permohonan menjadi tertunda dan tidak bisa diselesaikan dengan tepat waktu.

d. Surat Perintah Kerja (SPK) Pandu adalah dokumen yang berisi perintah untuk melaksanakan pelayanan kapal yang dikeluarkan oleh Badan Usaha Pelabuhan (BUP) yang meliputi kegiatan pemanduan, penundaan, dan tambat kapal. SPK Pandu biasa digunakan dalam kegiatan pemanduan kapal masuk dan kapal pindah (Shiting) dan kapal keluar. Kendala yag terdapat disini adalah pada saat pengurusan SPK Pandu melalui system aplikasi IBS (Integrated Billing System) PELINDO ada kalanya system 
mengalami gangguan sehingga mengakibatkan tertundanya pemberitahuan pemanduan kapal kepada pihak PELINDO.

\section{SIMPULAN DAN SARAN}

PT. Arpeni Pratama Ocean Line Banjarmasin adalah perusahaan pelayaran yang bergerak dibidang keagenan kapal baik kapal vessel maupun kapal tugboat yang bertugas seperti pada Mengusahakan muatan, Mengurus bongkar muat barang, Mengurus kebutuhan awak kapal (misalnya ABK sakit memerlukan ambulan untuk pengobatan, pengurusan dahsuskim untuk crewdan tenaga ahli asing merupakan salah satu tugas dari agen), Mengurus Clearance kapal masuk dan keluar di pelabuhan, Mengurus kebutuhan kapal, bunker, air tawar, bahan bakar dan bahan makanan, dan Menyelesaikan dokumendokumen muatan, Dalam pengerjaan keagenan kapalnya PT. Arpeni Pratama Ocean Line Banjarmasin menerapkan Standar Opersional Prosedur melalui Menunjang kelancaran dalam proses pelaksanaan tugas dan kemudahan pengendalian, Mempertegas tanggung jawab pelaksanaan tugas serta meningkatkan dayaguna dan hasilguna secara berkelanjutan dan Memberikan informasi pelaksanaan tugas yang dilakukan secara proporsional. Penerpan Standar Operasional Prosedur PT. Arpeni Pratama Ocean Line saat melayani keagenan kapal terdapat baik pada Kedatangan kapal, Kapal Pindah (shifting) dan Keberangkatan Kapal

\section{DAFTAR PUSTAKA}

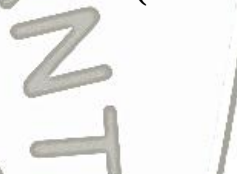

Undang - Undang 5 Tahun 2014 Pasal11 tentang Aparatur Sipil NegaraPeraturan Menteri Perhubungan Republik Indonesia No. 65 tahun 2019 tentang Penyelenggaraan dan Pengusahaan Keagenan Kapal Pasal 1 Ayat 4

Peraturan Menteri Perhubungan Nomor: KM. 21 Tahun 2007 tentang Sistem dan Prosedur Pelayanan Kapal, Barang dan Penumpang pada Pelabuhan Laut

Peraturan Menteri Perhubungan Republik Indonesia Nomor: PM. 51 Tahun 2015 tentang Penyelenggaran Pelabuhan Laut Pasal 1 Ayat 12

Peraturan Menteri Kesehatan Nomor: 2348/MENKES/PER/XI/2011 tanggal 22 November 2011

Peraturan Pemerintah Republik Indonesia Nomor 5 Tahun 2010 Tentang Kenavigasian Pasal 1 Ayat 1

Permenpan.No.PER/21/M-PAN/11/2008 http://baharisejahterajogjakarta.blogspot.com/2017/01/keagenan-kapal.html http://repository.pip-semarang.ac.id/873/3/13-BAB\%201.PDF https://docplayer.info/47152226-Bab-3-analisis-sistem-berjalan.html 